\title{
Nutritional and Plasma Antioxidant Status Assessment in a Group of Old Alzheimer's Inpatients
}

\author{
Giovanna Turconi ${ }^{1 *}$, Paolo Simonetti ${ }^{2}$, Antonella Brusamolino ${ }^{2}$, Mariangela Rondanelli ${ }^{3}$, Carla Roggi ${ }^{1}$ and Hellas Cena ${ }^{1}$ \\ ${ }^{1}$ Department of Applied Health Sciences, Section of Human Nutrition, University of Pavia, Italy \\ ${ }^{2}$ DISTAM, Sezione Nutrizione, Università degli studi di Milano, Italy \\ ${ }^{3}$ Department of Applied Health Sciences, Section of Human Nutrition, University of Pavia, Santa Margherita Geriatric Hospital Pavia, Italy 3Department of Applied Health \\ Sciences, Section of Human Nutrition, University of Pavia, Santa Margherita Geriatric Hospital Pavia, Italy
}

\begin{abstract}
This study was carried out to assess the nutritional and plasma antioxidant status of Alzheimer's inpatients compared to age-matched controls by means of anthropometric measurements, neuropsychological and nutritional tests and plasma biomarkers. Assessment of nutritional biomarkers of prooxidant/antioxidant balance in patients with $\mathrm{AD}$ as well as nutritional status and neuropsychological evaluation are important since many studies have demonstrated their association with cognitive impairment.

This cross sectional study was carried out in 35 subjects recruited in a geriatric institution in Pavia, Northern Italy.

Cases mean Body Mass Index (BMI) was lower than controls' one as well as mid arm circumference, triceps skinfold and arm muscle circumference. Both inpatients MNA and MMSE mean scores were lower than controls ones. Plasma levels of lutein plus zeaxanthin, beta-cryptoxanthin, lycopene, alfa tocopherol, ascorbic acid were significantly lower $(p<0.05)$ in $A D$ in patients as well as superoxide desmutase and glutathione peroxidase concentrations, while all the other biochemical markers levels did not differ.
\end{abstract}

Plasma antioxidant levels and activities were decreased in $A D$ and could be biologically predictive of an early mild cognitive decline, suggesting early intervention on dietary antioxidant intake.

Keywords: Alzheimer's disease; Nutritional assessment; MNA; MMSE; Antioxidant plasma levels

\section{Introduction}

Oxidative stress has been implicated in mechanisms leading to neuronal cell injury in various pathological states of the brain. Accumulated damage to lipid membranes and DNA by oxygen free radicals and reactive oxygen species is thought to disrupt normal cell functioning and lead to neuronal death. Alzheimer's disease $(\mathrm{AD})$ is a progressive disorder with cognitive and memory decline, speech loss, personality changes and synapse loss. Many studies suggest that oxidative damage is one of the factors in the neuronal death underlying the loss of cognition [1-4].

Antioxidant nutrients, including vitamin E, vitamin $\mathrm{C}$, and carotenoids, are among the body's natural defense mechanisms against oxidative stress [5-8]. The antioxidant nutrients have been shown through animal and laboratory studies of brain tissue to decrease lipid peroxidation $[9,10]$, and the oxidation of proteins $[11,12]$, inhibit the production of reactive oxygen species [13], prevent mitochondrial dysfunction [14] and DNA fragmentation [15], and reduce neurotoxicity [16,17], apoptosis [18], and neuronal death [19].

The results of some large community studies, Eva study [20] and the Chicago Health and Aging Project [21], demonstrated that the increased levels of oxidative stress [22] and/or antioxidant deficiencies may pose risk factors for cognitive decline, even when controlled for nutritional status.

Consequently, the effects of intake of antioxidant nutrients and flavonoids, in the prevention of cognitive impairment and dementia, have been widely investigated [23-27].

Given this background, assessment of nutritional biomarkers of prooxidant/antioxidant balance in patients with $\mathrm{AD}$ is important since the many studies above described have demonstrated the association between cognitive impairment and antioxidant status in this population.

Besides nutritional status in older adults is an issue of increasing importance, especially in demented patients, at risk of malnutrition. In the elderly, chronic co-morbidities are more difficult to treat for the potentially bad nutritional conditions. Malnutrition is a condition associated with functional and cognitive decline in the demented elderly.

The aim of this study was to assess the nutritional and plasma antioxidant status of old Alzheimer's inpatients compared to agematched controls by means of anthropometric measurements, neuropsychological and nutritional tests and the evaluation of the following biomarkers plasma levels: GSH levels (total and oxidized), glutathione peroxidase, superoxide desmutase, ascorbic acid, retinol, alfa tocopherol, lutein plus zeaxanthin, beta-cryptoxanthin, alphacarotene, beta-carotene, lycopene.

*Corresponding author: Giovanna Turconi, Department of Applied Health Sciences - Section of Human Nutrition -Via Bassi, 21 - 27100 Pavia, Italy, Tel + 39 0382 987544; Fax: + 390382 987570; E-mail: gturconi@unipv.it

Received February 10, 2011; Accepted March 26, 2011; Published March 29 2011

Citation: Turconi G, Simonetti P, Brusamolino A, Rondanelli M, Roggi C, et al (2011) Nutritional and Plasma Antioxidant Status Assessment in a Group of Old Alzheimer's Inpatients. J Nutr Food Sci 1:101. doi:10.4172/2155-9600.1000101

Copyright: @ 2011 Turconi G, et al. This is an open-access article distributed under the terms of the Creative Commons Attribution License, which permits unrestricted use, distribution, and reproduction in any medium, provided the original author and source are credited. 


\section{Material and Methods}

\section{Sampling}

Twenty-one subjects with AD (5 males and 16 females) and 14 controls ( 4 males and 10 females), aged 65-92 years, have been recruited at Santa Margherita Hospital in Pavia, Italy, a geriatric institution. All the 21 inpatients affected by $\mathrm{AD}$, once diagnosed, had been hospitalized since October- December 2007, while the controls were outpatients in good health.

Diagnosis of $\mathrm{AD}$ was made according to criteria of the National Institute of Neurological and Communicative Disorders and Stroke and Alzheimer's disease and Related Dementia Association (NINCDSADRDA) [28].

A brief interview was conducted with inpatients' relatives as well as with all the outpatients to assess familiarity for AD.

The research protocol was approved by both the Ethics Committee of the Faculty of Medicine of the University of Pavia and the Ethics Committee of the Geriatric Institution.

Informed written consent was obtained from each outpatient and from the inpatients' relatives.

\section{Anthropometric measurements}

- All the subjects had been examined by health personnel (medical doctors and dietitians) and the following parameters weWeight, measured on subjects wearing only underwear and without shoes by means of a steelyard scale;

- Stature, estimated by knee height measurement;

- Mid-triceps skin folds thickness measured on subjects according to standard conditions using a Harpenden skin fold thickness calliper; three consecutive measurements were performed and the mean of the three values was considered;

- Mid arm circumference, measured on subjects according to standard conditions using a measuring tape.

BMI was calculated as a ratio between weight and height squared with weight in kilograms and height in meters while arm muscle circumference was computed according to standard equation of Frisancho [29].

\section{Neuropsychological and nutritional tests}

The Mini-Mental State Examination (MMSE) [30], the most commonly used mental status test with the elderly, has been performed on all 35 subjects as well as the Mini Nutritional Assessment (MNA) [31] in order to assess nutritional status of the enrolled subjects.

\section{Biochemical measurements}

Chemicals: Ascorbic acid, formic acid, retinol, a-tocopherol, lutein, $\beta$-carotene and lycopene were from Sigma Chemical. Other carotenoids and echinenone were from F. Hoffmann-La Roche \& Co., Basel, Switzerland

\section{Biochemical analysis}

Carotenoids, retinol and tocopherol determination in plasma: Blood samples were collected in tubes containing lithium-heparin and centrifuged at $1000 \mathrm{x} g$ for $10 \mathrm{~min}$ to obtain plasma and red blood cells. After separation, $100 \mathrm{~L}$ of ethanol containing echinenone as internal standard were added to $100 \mu \mathrm{L}$ plasma. The samples were immediately vortexed therefore $250 \mu \mathrm{L}$ of hexane were added for analytes extraction.
Samples were vortexed again for $1 \mathrm{~min}$ and centrifuged at $1000 \mathrm{xg}$ for 5 min, supernatant $(200 \mu \mathrm{L})$ was recovered, evaporated under $\mathrm{N}_{2}$ atmosphere and stored at $-80^{\circ} \mathrm{C}$ until analysis. For HPLC separation samples were dissolved in $100 \mu \mathrm{L}$ of methanol-tetrahydrofuran (MetOH: THF, 90:10) immediately before analysis.

The chromatographic system (HPLC) used for separation and quantification of carotenoids and vitamins consisted of an Alliance model 2695 (Waters, Milford, MA, USA) equipped with a model 2996 (Waters) photodiode array detector. All data were acquired by Empower 2 Chromatography Data Software (Waters) [32].

A $5 \mathrm{~mm}$ Vydac 201TP54 C18 column $(250$ x $4.6 \mathrm{~mm}$; Vidac, Esperia, CA, USA) fitted with a C18 guard column and biocompatible frits was used for the separation of carotenoids, retinol and -tocopherol which was performed by means of a linear gradient elution (eluent $\mathrm{A}$, methanol; eluent B, THF) at a flow rate of $1.2 \mathrm{ml} / \mathrm{min}$. The gradient was as follows: from 100 to $95 \% \mathrm{~A}$ in $5 \mathrm{~min}$, from 95 to $85 \% \mathrm{~A}$ in $15 \mathrm{~min}$ and then from 85 to $100 \% \mathrm{~A}$ in $10 \mathrm{~min}$.

Chromatographic data were acquired in the 200-600 nm range and were integrated at $445 \mathrm{~nm}$ for lutein, zeaxanthin, $\beta$-cryptoxanthin, echinenone and $\alpha$ - and $\beta$-carotene (Figure 1), at $472 \mathrm{~nm}$ for lycopene, at $325 \mathrm{~nm}$ for retinol and at $292 \mathrm{~nm}$ for tocopherol.

Carotenoids concentrations were calculated by means of a mix of standards in the range $0.1-1.0 \mu \mathrm{g} / \mathrm{ml}$ containing lutein, zeaxanthin, $\beta$-cryptoxanthin $\alpha$-carotene and $\beta$-carotene while lycopene was prepared daily (to avoid degradation) and injected separately. Data were corrected by recovery of the internal standard. Retinol and tocopherol were quantified by calibration curves obtained daily before sample analysis by injecting increasing amounts of the standards (dissolved in ethanol) in the range $0.5-5 \mu \mathrm{g} / \mathrm{ml}$ (retinol) and 2-20 $\mu \mathrm{g} /$ $\mathrm{ml}$ (tocopherol).

Ascorbic acid determination in plasma: Immediately after blood centrifugation plasma was separated and acidified using an equal volume of metaphosphoric acid (MPA) 10\% (w/v) solution (100 $\mu \mathrm{L}$ plasma $+100 \mu \mathrm{L} \mathrm{MPA})$. Samples were stored at $-80^{\circ} \mathrm{C}$ for 7 days.

At the time of determination the samples were vortexed and centrifuged at $2000 \mathrm{xg}$ for $1 \mathrm{~min}$, and $50 \mu \mathrm{L}$ of the supernatant were immediately injected for HPLC analysis.

The chromatographic system is the same of that above-mentioned and the chromatographic data were acquired at $245 \mathrm{~nm}$.

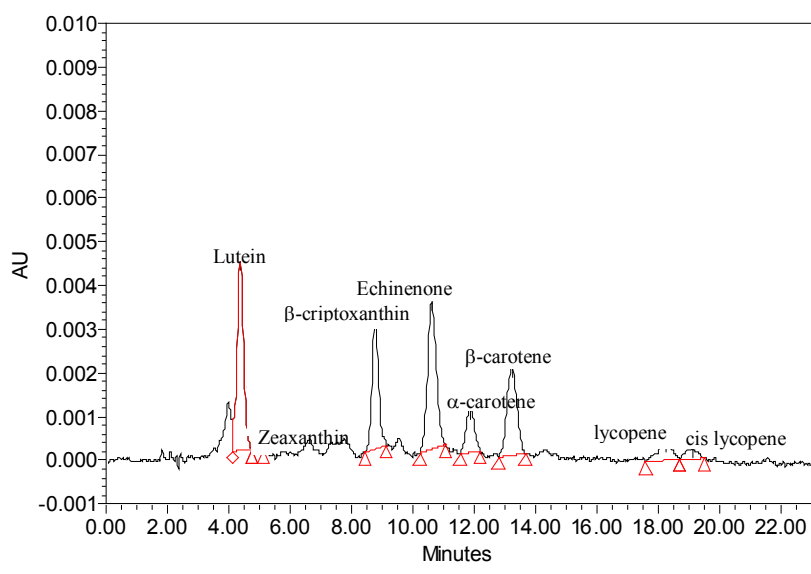

Figure 1: Typical HPLC chromatogram at $445 \mathrm{~nm}$ of plasma sample. 
A $5 \mathrm{~mm}$ Atlantis C18 column $(250 \times 4.6 \mathrm{~mm}$; Waters $)$ fitted with a C18 guard column was used for the separation of ascorbic acid and the flow rate was fixed to $1.4 \mathrm{ml} / \mathrm{min}$. The eluent was formic acid $0.1 \%$.

Ascorbic acid standard solutions were prepared daily by dissolving standard power in MPA $10 \%$ to obtain calibration curves in a range of concentrations of $2.5-20 \mu \mathrm{g} / \mathrm{ml}$.

Erythrocytes enzymes activity determination: Erythrocytes lysate were prepared according to kit indications (Cayman Chemical Company, Ann Arbor, MI, USA). Briefly, blood was centrifuged at 1000 $\mathrm{x} g$ for $10 \mathrm{~min}$ at $4^{\circ} \mathrm{C}$, than plasma and buffy layer were removed and erythrocytes were lysed by adding 4 volumes of ice-cold HPLC grade water. Samples were centrifuged at $10000 \mathrm{x} g$ for $15 \mathrm{~min}$ at $4^{\circ} \mathrm{C}$ and supernatant was aliquoted in vials and stored at $-80^{\circ} \mathrm{C}$ until analysis.

Superoxide dismutase, glutathione peroxidase activities and GSH levels (total and oxidized) were measured by means Cayman kits (cod. 706002 , cod. 703102 and cod. 703002 respectively) and by using a plate reader at $450 \mathrm{~nm}, 340 \mathrm{~nm}$ and $405 \mathrm{~nm}$ respectively. Results were expressed in $\mathrm{U} / \mathrm{mg} \mathrm{Hb}$ for SOD activity, $\mathrm{mU} / \mathrm{g} \mathrm{Hb}$ for GSH-Px and $\mu \mathrm{mol} / \mathrm{g} \mathrm{Hb}$ for GSH and GSSG.

\section{Statistical analysis}

The data analyses were performed using the Statistical Package for the Social Science/PC version 10, Chicago- SPSS Inc. T-student test was used to compare results between the two groups of elderly. Multiple regression analysis was carried out to verify the impact of the anthropometric and biochemical measurements on MNA and on MMSE respectively.

\section{Results}

Sample characteristics (Mean \pm Standard Deviation) are reported in Table 1. All the variables were statistically different, except age.

All the inpatients had good deambulation although not self sufficient, 13 and 8 of them had good or moderate chewing ability respectively; 16 and 5 of them had a moderate or good visus respectively. Six of them had one or more relatives with AD.

All the controls had good deambulation and were self sufficient, with good chewing ability; 12 and 2 of them had a good or moderate visus respectively. All the controls were in good health, $64 \%$ of them suffer from hypertension, diabetes and asthma, but were pharmacologically well compensated. Cases mean BMI was lower than controls' one as well as mid arm circumference, triceps skinfold and arm muscle circumference.

Thirteen cases were normal weight according to BMI, 6 were overweight and 2 were underweight, while 5 controls were normal weight, 7 were overweight and 2 were obese.

\begin{tabular}{|l|c|c|c|c|c|}
\hline \multicolumn{1}{|c|}{ Variables } & \multicolumn{2}{c|}{ Cases $(\mathbf{n = 2 1 )}$} & \multicolumn{2}{c|}{ Controls $(\mathbf{n = 1 4 )}$} & T-Test \\
\hline & mean & S.D. & mean & S.D. & p value \\
\hline Age $(\mathrm{yrs})$ & 81.5 & 5.5 & 78.8 & 3.2 & 0.1072 \\
\hline BMI $\left(\mathrm{kg} / \mathrm{m}^{2}\right)$ & 23.2 & 3.1 & 26.5 & 4.7 & $<0.01$ \\
\hline Mid Arm Circumference $(\mathrm{cm})$ & 24.4 & 3.6 & 28.6 & 3.2 & $<0.001$ \\
\hline Triceps Skinfold $(\mathrm{mm})$ & 11.1 & 4.9 & 17.7 & 6.8 & $<0.002$ \\
\hline Arm Muscle Circumference $(\mathrm{cm})$ & 20.9 & 2.6 & 23.1 & 3.0 & $<0.05$ \\
\hline MNA* score $^{*}$ ) & 18.5 & 4.0 & 27.6 & 1.2 & $<0.0001$ \\
\hline MMSE† score $^{*}$ & 18.4 & 5.9 & 29.2 & 0.8 & $<0.0001$ \\
\hline
\end{tabular}

${ }^{*}$ Mini Nutritional Assessment test; ${ }^{\dagger}$ Mini-Mental State Examination test

Table 1: Sample characteristics.

\begin{tabular}{|c|c|c|c|c|c|}
\hline \multirow[t]{2}{*}{ Biomarkers } & \multicolumn{2}{|l|}{$\begin{array}{l}\text { Cases } \\
(n=21)\end{array}$} & \multicolumn{2}{|c|}{$\begin{array}{l}\text { Controls } \\
(n=14)\end{array}$} & \multirow{2}{*}{$\begin{array}{l}\text { T-Test } \\
\text { p value }\end{array}$} \\
\hline & mean & S.D. & mean & S.D. & \\
\hline Total GSH $(\mu \mathrm{mol} / \mathrm{g} \mathrm{Hb})$ & 7.16 & 1.48 & 6.71 & 1.30 & 0.369 \\
\hline GSSG $(\mu \mathrm{mol} / \mathrm{g} \mathrm{Hb})$ & 0.64 & 0.21 & 0.63 & 0.15 & 0.837 \\
\hline $\mathrm{GPx}(\mathrm{U} / \mathrm{g} \mathrm{Hb})$ & 15.68 & 4.40 & 18.11 & 3.9 & $<0.05$ \\
\hline $\mathrm{SOD}(\mathrm{U} / \mathrm{mg} \mathrm{Hb})$ & 2.98 & 0.59 & 3.13 & 0.89 & $<0.05$ \\
\hline Ascorbic Acid $(\mu \mathrm{mol} / \mathrm{L})$ & 44.69 & 27.06 & 71.88 & 20.65 & $<0.05$ \\
\hline Retinol $(\mu \mathrm{g} / \mathrm{mL})$ & 1.56 & 0.72 & 1.64 & 1.07 & 0.776 \\
\hline$\alpha$ tocopherol, $(\mu \mathrm{g} / \mathrm{mL})$ & 13.90 & 4.59 & 20.68 & 4.18 & $<0.001$ \\
\hline Lutein + Zeaxanthin $(\mu \mathrm{mol} / \mathrm{mL})$ & 0.49 & 0.21 & 0.67 & 0.28 & $<0.05$ \\
\hline$\beta$ cryptoxanthin $(\mu \mathrm{mol} / \mathrm{mL})$ & 0.44 & 0.50 & 0.97 & 0.83 & $<0.05$ \\
\hline$\alpha$ Carotene $(\mu \mathrm{mol} / \mathrm{mL})$ & 0.12 & 0.10 & 0.11 & 0.08 & 0.811 \\
\hline$\beta$ Carotene $(\mu \mathrm{mol} / \mathrm{mL})$ & 0.51 & 0.37 & 0.55 & 0.51 & 0.819 \\
\hline Lycopene $(\mu \mathrm{mol} / \mathrm{mL})$ & 0.20 & 0.09 & 0.21 & 0.18 & $<0.05$ \\
\hline
\end{tabular}

Table 2: Antioxidant plasma levels in the elderly.

Mean mid arm circumference of the cases was below the $5^{\text {th }}$ percentile while the controls' one was between the $25^{\text {th }}$ and $50^{\text {th }}$ percentiles [33].

The triceps skinfolds of the cases were below the $25^{\text {th }}$ percentile in all the females ( 6 between the $10^{\text {th }}$ and $25^{\text {th }}$ percentiles and 5 below the $5^{\text {th }}$ percentile) and between the $25^{\text {th }}$ and $50^{\text {th }}$ percentiles in all the males (cases and controls) while 4 control females were between the $5^{\text {th }}$ and $10^{\text {th }}$ percentiles and 6 were between the $50^{\text {th }}$ and $75^{\text {th }}$ percentiles [33].

As far as arm muscle circumference concerns 6 cases were below the $5^{\text {th }}$ percentile, 2 were between the $5^{\text {th }}$ and $10^{\text {th }}$ percentiles, 7 were between the $10^{\text {th }}$ and $25^{\text {th }}$ percentiles and 6 over the $25^{\text {th }}$ percentile.

On the other hand none of the controls set below the $10^{\text {th }}$ percentile, 8 were between the $10^{\text {th }}$ and $25^{\text {th }}$ percentiles and 6 over the $50^{\text {th }}$ percentile [33].

Both inpatients MNA and MMSE mean scores were lower than controls ones.

All the controls were well nourished, with MNA scores more than 24, while 15 cases were at risk of energy-protein malnutrition (MNA between 17 and 23,5) and $6 \mathrm{AD}$ patients were severely malnourished $(\mathrm{MNA}<17)[31]$.

All the controls scored MMSE more than 24, while 19 cases scored between 10 and 24 (moderate $\mathrm{AD}$ ) and 2 scored less than 10 (severe AD) [30].

MMSE and MNA in the total sample were significantly correlated $(\mathrm{R}=0.72 ; \mathrm{p}<0.01)$.

Multiple regression analysis carried out to verify the impact of the two circumferences (mid arm circumference and arm muscle circumference), the triceps skinfolds, BMI and MNA on MMSE in the total sample, showed that MNA is the most closely and significantly correlated $(\mathrm{R}=0.70 ; \mathrm{P}<0.001)$.

Biochemical markers values (Mean Standard Deviation) are reported in Table 2.

Plasma levels of lutein plus zeaxanthin, beta-cryptoxanthin, lycopene, alfa tocopherol, ascorbic acid were significantly lower $(\mathrm{p}<$ 0.05) in $\mathrm{AD}$ inpatients.

Superoxide desmutase and glutathione peroxidase concentrations were significantly lower $(\mathrm{p}<0.05)$ in $\mathrm{AD}$ inpatients too.

All the other biochemical markers levels did not differ between cases and controls. 
Multiple regression analysis carried out to verify the impact of all the carotenoids, vitamins and antioxidant enzymes measured on MNA in the total sample, showed that only antioxidant vitamins were significantly correlated $(\mathrm{R}=0.75 ; \mathrm{p}<0.001)$. The same analysis carried out to verify the impact of the biochemical markers over reported on the MMSE in the total sample, showed that, also in this case, only antioxidant vitamins were significantly correlated ( $R=0.73$; $p<0.001)$.

\section{Discussion}

In our sample all the cases showed a worse nutritional status compared to controls, data confirmed by MNA scores as well as by anthropometric measurements: fifteen subjects were at risk of malnutrition while six subjects were frankly malnourished.

A comprehensive geriatric assessment including nutritional status is recommended in all the elderly population, at risk of malnutrition as reported by many authors [34-37], for a better care both in institutionalized and free living subjects.

AD could result from an acceleration of the normal ageing process in brain regions particularly sensitive to free radical damage. Antioxidants could, therefore, play an important role in preventing the deleterious actions of free radicals in brains. Most of the antioxidants measured were lower in the $\mathrm{AD}$ patients compared to the controls. This may be partly due to the different nutritional status of the two groups and probably to the different dietary intake of the antioxidant nutrients. It would have been interesting to estimate dietary intakes of these nutrients, but there is not any valid method of dietary assessment specific for dement subjects unless the weighted method which is difficult to carry out. The absence of the antioxidants nutrition assessment in this sample is a study limit.

A large body of evidence shows that the risk of elderly subjects to develop $\mathrm{AD}$ increases every year; there are epidemiological studies showing a direct relationship between plasma antioxidant levels and cognitive performance [38] and between risk of cognitive decline and plasma levels of lipid peroxidation markers in humans [39].

In a study carried out by Rinaldi et al. [40], the modification of several components of the antioxidant defence system of the organism are shown both in $\mathrm{MCI}$ and $\mathrm{AD}$ subjects compared to healthy subjects. In this study the authors state that the antioxidant depletion is unlikely due to the presence of malnutrition, excluded by the thorough nutritional assessment performed in all subjects. In our study plasma levels of lutein plus zeaxanthin, beta-cryptoxanthin, lycopene, alfa tocopherol, ascorbic acid were significantly depleted in $\mathrm{AD}$ inpatients when compared to controls. This could be due to the presence of malnutrition as assessed in our AD group but even though studies support the hypothesis that subjects with $\mathrm{AD}$ are malnourished, particularly in the last phase of the disease, several recent researches demonstrate lower plasma antioxidant levels in the early $\mathrm{AD}$ stages also in well-nourished subjects $[41,42]$.

In our study, the depleted levels of antioxidant vitamins in $\mathrm{AD}$ patients showed that the major components of the antioxidant defence system were affected in this condition. Antioxidants such as vitamin $\mathrm{C}$ play an important role in preventing the deleterious actions of free radicals in brains as well as a pathophysiological one in metal-mediated oxidative stress in AD [43]. Vitamin C is actively concentrated in the brain and is implicated in noradrenalin synthesis. Furthermore, this soluble antioxidant is considered to be the first barrier to free radicals produced in biological fluids, whereas vitamin $\mathrm{E}$ is a major element which breaks the peroxidation chain in membranes [44]. Its status is known to be inversely associated with cognitive performance in the elderly [45].

Although $\alpha$ and $\beta$ Carotene did not differ in our sample, the antioxidant potential of carotenoids and retinol is gaining increasing attention with respect to dementing disorders [41,46]

$\mathrm{AD}$ patients in our study showed lower levels of lutein, zeaxanthin, $\beta$-cryptoxanthin and lycopene as compared to controls, in agreement with other studies reporting that these carotenoids seem to be efficient quenchers of singlet molecular oxygen and scavengers of peroxyl radicals $[40,47]$.

The observed decrease in plasma levels of plasma SOD and GPx activities in $\mathrm{AD}$ patients in comparison to controls might be explained by a high free radical production occurring in this condition due to a rapid consumption of plasma antioxidants without a simultaneous activation of the antioxidant enzymes. Subjects developing AD may have a lower antioxidant enzymatic activity inadequate to counteract the hyper-production of free radicals during a condition of oxidative stress.

In conclusion the present study showed that plasma antioxidant levels and activities were decreased in AD. Although it was carried out on a small sample, the many antioxidant biomarkers tested suggested that the measurement of oxidative stress markers [46,48-50] could be used in the elderly in order to biologically predict an early mild cognitive decline evolving in $\mathrm{AD}$. These measurements may be helpful to correct an antioxidant imbalance [51] and prevent or delay cognitive deterioration by means of diets containing high levels of antioxidants prior to the development of an $\mathrm{AD}$.

\section{Declaration of Interest}

The authors state that there are no competing financial interests in relation to the work described or any financial or other contractual agreements that might cause conflicts of interest.

\section{References}

1. Berr C (2002) Oxidative stress and cognitive impairment in the elderly. J Nutr Health Aging 6: 261-266

2. Birkner E, Zalejska-Fiolka J, Antoszewski Z (2004) Activity of antioxidant enzymes and the role of antioxidant vitamins in Alzheimer disease. Postepy Hig Med Dosw 58: 264-269.

3. Behl C, Moosmann B (2002) Antioxidant neuroprotection in Alzheimer's disease as preventive and therapeutic approach. Free Radic Biol Med 33: 182-191.

4. Markesbery WR, Carney JM (1999) Oxidative alterations in Alzheimer's disease. Brain Pathol 9: 133-146.

5. Halliwell B (1996) Antioxidants in human health and disease. Ann Rev Nutr 16: 33-50.

6. Sies H, Stahl W (1995) Vitamins E and C, beta-carotene, and other carotenoids as antioxidants. Am J Clin Nutr 62: I3I5S-132IS.

7. Farbstein D, Kozak-Blickstein A, Levy AP (2010) Antioxidant vitamins and their use in preventing cardiovascular disease. Molecules 15: 8098-8110.

8. Riccioni G, Mancini B, Di llio E, Bucciarelli T, D'orazio N (2008) Protective effect of lycopene in cardiovascular disease. Eur Rev Med Pharmacol Sci 12: 183190

9. Inci S, Ozcan OE, Kilinc K (1998) Time-level relationship for lipid peroxidation and the protective effect of alpha-tocopherol in experimental mild and severe brain injury. Neurosurgery 43: 330-335.

10. Guerrero AL, Dorado-Martinez C, Rodriguez A, Pedroza-Rios K, BorgonioPerez G, et al. (1999) Effects of vitamin E on ozone-induced memory deficits and lipid peroxidation in rats. Neuroreport 10: 1689-1692.

11. Subramaniam R, Koppal T, Green M, Yatin S, Jordan B, et al. (1998) The free radical antioxidant vitamin $\mathrm{E}$ protects cortical synaptosomal membranes 
Citation: Turconi G, Simonetti P, Brusamolino A, Rondanelli M, Roggi C, et al. (2011) Nutritional and Plasma Antioxidant Status Assessment in a Group of Old Alzheimer's Inpatients. J Nutr Food Sci 1:101. doi:10.4172/2155-9600.1000101

from amyloid beta-peptide(25-35) toxicity but not from hydroxynonenal toxicity: relevance to the free radical hypothesis of Alzheimer's disease. Neurochem Res 23: 1403-1410.

12. Zhang P, Omaye ST (2000) Beta-carotene and protein oxidation: effects of ascorbic acid and alpha-tocopherol. Toxicology 146: 37-47.

13. Cardoso SM, Pereira C, Oliveira CR (1998) The protective effect of vitamin E, idebenone and reduced glutathione on free radical mediated injury in rat brain synaptosomes. Biochem Biophys Res Commun 246: 703-710.

14. Bertoni-Freddari C, Fattoretti P, Caselli U, Paoloni R, Meier-Ruge W (1995) Vitamin $\mathrm{E}$ deficiency as a model of precocious brain aging: assessment by X-ray microanalysis and morphometry. Scanning Microsc 9: 289-301.

15. Tagami M, Yamagata K, Ikeda K, Nara Y, Fujino H, et al. (1998) Vitamin E prevents apoptosis in cortical neurons during hypoxia and oxygen reperfusion. Lab Invest 78: 1415-1429.

16. Yallampalli S, Micci MA, Taglialatela G (1998) Ascorbic acid prevents betaamyloid-induced intracellular calcium increase and cell death in PC12 cells. Neurosci Lett 251: 105-108.

17. Huang HM, Ou HC, Hsieh SJ (2000) Antioxidants prevent amyloid peptideinduced apoptosis and alteration of calcium homeostasis in cultured cortical neurons. Life Sci 66: 1879-1892.

18. Ahlemeyer B, Krieglstein J (2000) Inhibition of glutathione depletion by retinoic acid and tocopherol protects cultured neurons from staurosporine-induced oxidative stress and apoptosis. Neurochem Int 36: 1-5.

19. Sen CK, Khanna S, Roy S, Packer L (2000) Molecular basis of vitamin E action. Tocotrienol potently inhibits glutamate-induced pp60(c-Src) kinase activation and death of HT4 neuronal cells. J Biol Chem 275: 13049-13055.

20. Berr C, Balansard B, Arnaud J, Roussel AM, Alpérovitch A (2000) Cognitive decline is associated with systemic oxidative stress: the EVA study. Etude du Vieillissement Artériel. J Am Geriatr Soc 48: 1285-1291.

21. Morris MC, Evans DA, Bienias JL, Tangney CC, Bennett DA, et al. (2002) Dietary intake of antioxidant nutrients and the risk of incident Alzheimer disease in a biracial community study. JAMA 287: 3230-3237

22. Sánchez-Rodríguez MA, Santiago E, Arronte-Rosales A, Vargas-Guadarrama LA, Mendoza-Núñez VM (2006) Relationship between oxidative stress and cognitive impairment in the elderly of rural vs. urban communities. Life Sci 78 : 1682-1687.

23. Commenges D, Scotet $V$, Renaud S, Jacqmin-Gadda H, Barberger-Gateau $P$ et al. (2000) Intake of flavonoids and risk of dementia. Eur J Epidemiol 16: 357-363.

24. Paleologos M, Cumming RG, Lazarus R (1998) Cohort study of vitamin C intake and cognitive impairment. Am J Epidemiol 148: 45-50.

25. Jama JW, Launer LJ, Witteman JC, den Breeijen JH, Breteler MM, et al. (1996) Dietary antioxidants and cognitive function in a population-based sample of older persons. The Rotterdam Study. Am J Epidemiol 144: 275-280.

26. Wang W, Shinto L, Connor WE, Quinn JF (2008) Nutritional biomarkers in Alzheimer's disease: the association between carotenoids, $n-3$ fatty acids, and dementia severity. J Alzheimers Dis 13: 31-38.

27. Zandi PP, Anthony JC, Khachaturian AS, Stone SV, Gustafson D, et al. (2004) Reduced risk of Alzheimer disease in users of antioxidant vitamin supplements: the Cache County Study. Arch Neurol 61: 82-88.

28. McKhann G, Drachman D, Folstein M, Katzman R, Price D, et al. (1984) Clinical diagnosis of Alzheimer's disease: report of the NINCDS-ADRDA Work Group under the auspices of Department of Health and Human Services Task Force on Alzheimer's Disease. Neurology 34: 939-944.

29. Frisancho AR (1974) Triceps skinfold and upper arm muscle size norms for assessment of nutritional status. Am J Clin Nutr 27: 1052-1058.

30. Folstein MF, Folstein SE, McHugh PR (1975) "Mini-mental state". A practical method for grading the cognitive status of patients for the clinician. J Psychiatr Res 12: 189-198.
31. Gulgoz Y, Vellas B, Garry PJ (1996) Assessing the nutritional status of the elderly: The Mini Nutritional Assessment as part of the geriatric evaluation. Nutr Rev 54: S59-S65.

32. Riso P, Visioli F, Gardana C, Grande S, Brusamolino A, et al. (2005) Effects of blood orange juice intake on antioxidant bioavailability and on different markers related to oxidative stress. J Agric Food Chem 53: 941-947.

33. Frisancho AR (1981) New norms of upper limb fat and muscle areas for assessment of nutritional status. Am J Clin Nutr 34: 2540-2545.

34. Scheltens $P$ (2009) Moving forward with nutrition in Alzheimer's disease. Eur J Neurol 16: S19-S22.

35. Gillette-Guyonnet S, Nourhashemi F, Andrieu S, de Glisezinski I, Ousset PJ, et al. (2000) Weight loss in Alzheimer disease. Am J Clin Nutr 71: 637s-642s.

36. Guerin O, Soto ME, Brocker P, Robert PH, Benoit M, et al. (2005) Nutritiona status assessment during Alzheimer's disease: results after one year (the REAL French Study Group). J Nutr Health Aging 9: 81-84.

37. Guérin O, Andrieu S, Schneider SM, Cortes F, Cantet C, et al. (2009) Characteristics of Alzheimer's disease patients with a rapid weight loss during a six-year follow-up. Clin Nutr 28: 141-146.

38. Schmidt R, Hayn M, Reinhart B, Roob G, Schmidt H, et al. (1998) Plasma antioxidants and cognitive performance in middle-aged and older adults: results of the Austrian stroke prevention study. J Am Geriatr Soc 46: 1407-1410.

39. Berr C, Balansard B, Arnaud J, Roussel AM, Alperovitch A (2000) Cognitive decline is associated with systemic oxidative stress: the EVA study. Etude du Vieillissement Artériel. J Am Geriatr Soc 48: 1285-1291.

40. Rinaldi P, Polidori MC, Metastasio A, Mariani E, Mattioli P, et al. (2003) Plasma antioxidants are similarly depleted in mild cognitive impairment and in Alzheimer's disease. Neurobiol Aging 24: 915-919.

41. Bourdel-Marchasson I, Delmas-Beauvieux MC, Peuchant E, Richard-Harston S, Decamps A, et al. (2001) Antioxidant defences and oxidative stress markers in erythrocytes and plasma from normally nourished elderly Alzheimer's patients. Age Ageing 30: 235-241

42. Riviere S, Birlouez-Aragon I, Nourhashemi F, Vellas B (1998) Low plasma Vitamin $C$ in Alzheimer patients despite an adequate diet. Int J Geriatr Psychiatry 13: 749-754.

43. Cuajungco MP, Faget KY, Huang X, Tanzi RE, Bush Al (2000) Metal chelation as a potential therapy for Alzheimer's disease. Ann NY Acad Sci 920: 292-304.

44. Azzi A, Stocker A (2000) Vitamin E: non-antioxidant roles. Prog Lipid Res 39 231-255.

45. Ortega RM, Requejo AM, Lopez-Sobaler AM, Andres P, Navia B, et al. (2002) Cognitive function in elderly people is affected by Vitamin E status. J Nutr 132 2065-2068.

46. Mecocci $P$, Polidori MC, Cherubini A, Ingegni T, Mattioli $P$, et al. (2002) Lymphocyte oxidative DNA damage and plasma antioxidants in Alzheime disease. Arch Neurol 59: 794-798.

47. Stahl W, Junghans A, de Boer B, Driomina ES, Briviba K, et al. (1998) Carotenoid mixtures protect multilamellar liposomes against oxidative damage: synergistic effects of lycopene and lutein. FEBS Lett 427: 305-308.

48. Beal MF (1995) Aging, energy, and oxidative stress in neurodegenerative diseases. Ann Neurol 38: 357-366.

49. Mecocci P, Polidori MC, Ingegni T, Cherubini A, Chionne F, et al. (1998) Oxidative damage to DNA in lymphocytes from AD patients. Neurology 51 1014-1017.

50. Praticò D, Clark CM, Liun F, Rokach J, Lee VY, et al. (2002) Increase of brain oxidative stress in mild cognitive impairment: a possible predictor of Alzheimer's disease. Arch Neurol 59: 972-976.

51. Meydani M (2001) Antioxidants and cognitive function. Nutr Rev 59: S75-S82. 